\title{
Gas and Biosensors Made from Metal Oxides Doped with Carbon Nanotubes
}

\author{
Aroutiounian VM* \\ Yerevan State University, Yerevan, Armenia
}

\section{Review Article}

Volume 5 Issue 1

Received Date: June 08, 2021

Published Date: June 29, 2021

DOI: $10.23880 / p s b j-16000176$

Email: aroutiounv1@yahoo.com

\section{Abstract}

Excellent physical properties of carbon nanotubes (CNTs) are used for the manufacturing many electronic devices. The single wall version of CNTs is promising for the detection of many important gases including gases exhaled by the living organism. The most promising is the realization of gas sensors based on metal oxides doped with CNTs. Application of CNT-based sensors to breath analysis, properties of the SWCNTs gas sensors with metal nanoparticles and metal oxides, and CNTs biosensors are reviewed in this paper.

Keywords: Metal Oxides; Gas; Nanotubes; Biosensers

\section{Introduction}

Carbon nanotubes (CNTs) have excellent mechanical and electrical properties. They allow for the use of CNTs in many applications, for example, for a wide range of electronic devices, including logic circuits [1], light-displaying devices [2], batteries [3], power semiconductor devices [4], and sensors [5-9]. CNTs were discovered about two decades ago [10]. They show a unique structure that can be envisioned as a graphene sheet rolled into tubular structure. CNTs can be either single-walled (i.e., SWCNT) or multi-walled (i.e., MWCNT) depending on the number of a concentric graphitic layers (Figure 1) [11]. The diameter is typically 1-10 $\mathrm{nm}$ for SWCNTs whereas it can be varied from 1 to over $100 \mathrm{~nm}$ for MWCNTs. The length of CNTs can also be varied in a broad range from several $\mathrm{nm}$ to over $1 \mathrm{~mm}$. The aspect ratio (length vs. diameter) of CNTs can be larger than $\sim 106$. CNTs are one of the materials with the highest known mechanical strength. The intrinsic tensile strength and Young's modulus can reach $1 \mathrm{TPa}$.

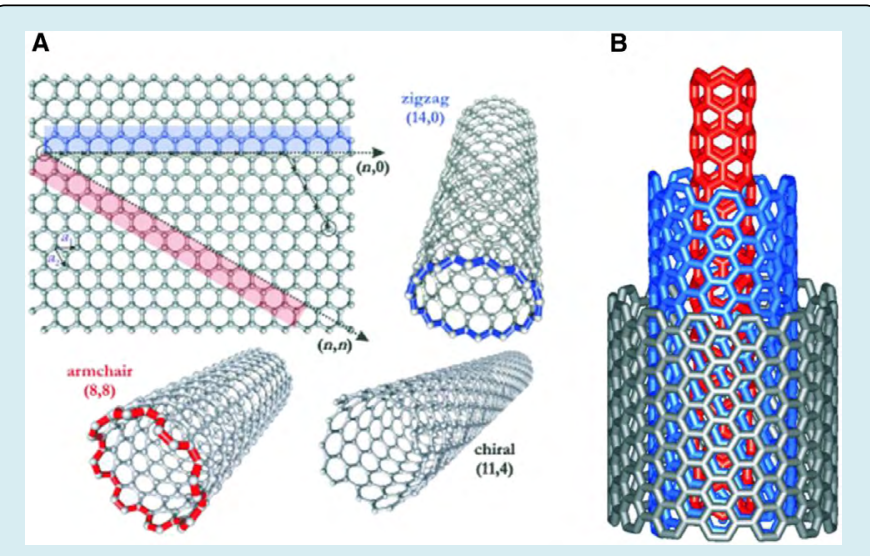

Figure 1: Depiction of (A) SWCNT with zigzag, armchair, and chiral structures, and (B) MWCNT with multiple concentric tubes of graphene [12].

Depending on the rolling angle of a graphene sheet (i.e., chirality), CNTs can be either semiconducting or metallic. 
In their metallic form, CNTs show a very high electrical conductivity with the capability of carrying electrical current over 50 times greater than typical metals. The electrical properties of CNTs are also potentially relevant to biomedical applications. MWCNTs are much less toxic than SWCNTs because of the differences in diameter and surface chemistry. A lot of papers about technology of preparation of CNTs are known. Only three papers in this field can be mentioned [1315]. CNTs are ideal materials for a new class of molecular sensors. CNT-based gas sensors have sensitive chemicalto-electrical transducer capability, high degree of chemical functionality options, and potential for miniaturization. Different semiconductor sensors are developed in Yerevan State University (Department of Physics of semiconductors and microelectronics and Research center of semiconductor devices and nanotechnology) in Armenia. Acetone, ammonia, benzene, butanol, i-butane, dichlorethane, dimethyl formamide, ethanol, formaldehyde, gasoline, hydrogen, hydrogen peroxide, iperit, methanol, natural gas, nitrogen oxides, propylene glycol, smoke, sulfurous anhydride , sulfurous oxides, toluene, zarin etc. nanosensors were developed in YSU [16-19]. Warfare chemical sensors were developed and investigated in the framework of the NATO grant. Beside experimental works, the structure and defects of metal oxide sensors were investigated using the density functional theory and empirical force fields. The electron density of states was computed. Independent testing of chemical warfare and smoke sensors in the USA and Czech
Republic were shown promise of their use.

\section{Detection of Gases Exhaled by the Organism}

Breath analysis is a promising method for rapid, inexpensive, noninvasive disease diagnosis and health monitoring owing to the correlative relationship between breath biomarker concentrations and abnormal health conditions. A type of an microelectronic monitor is shown in Figure 2.

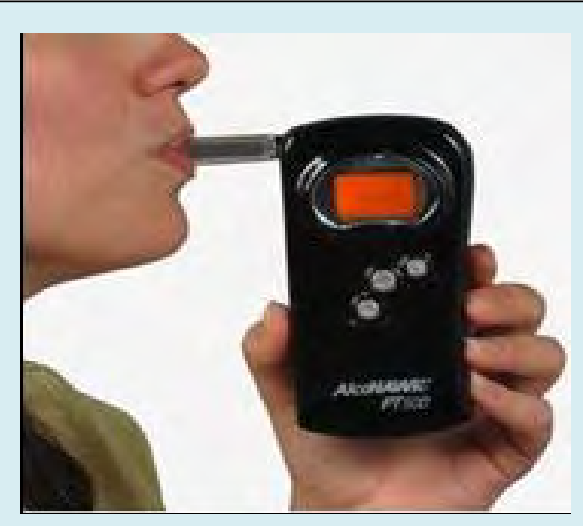

Figure 2: A type of an microelectronic breath monitor.

Breath biomarkers for various diseases are listed in Table 1 of our papers [20].

\begin{tabular}{|c|c|}
\hline Gases & Exhalation and diagnostic significance \\
\hline Nitrogen oxide (NO) & $\begin{array}{c}\text { Respiratory diseases [asthma, chronic obstructive pulmonary disease (COPD), etc.] Rhinitis } \\
\text { digestive diseases [inflammation in the stomach (gastritis, hepatitis, colitis), including } \\
\text { infection Helicobacter pylon digestive cancer Hyperthermia Heavy-textured sepsis Uremia }\end{array}$ \\
\hline Carbon monoxide (CO) & $\begin{array}{c}\text { Anemia (hemolytic, sideroblastic cell) Carboxy hemoglobinamija in acute and chronic } \\
\text { exposures Lasting stay at intakes Giperbilirubinonemia of newborn oxidative stress } \\
\text { hematoma Hemoglobinuria Pre-eclampsia of infection Thalassemia respiratory diseases } \\
\text { (asthma, COPD, infections of the respiratory infection Inflammation of lung) }\end{array}$ \\
\hline Ammonia $\left(\mathrm{NH}_{3}\right)$ & $\begin{array}{c}\text { Diseases of the kidneys and liver (renal insufficiency in nephritis, idiopathic hypertension, } \\
\text { atherosclerosis of renal artery, toxicosis and nephropathy of pregnant, toxic defeats of } \\
\text { kidneys, paucity of the liver in jaundice, hepatitis, cirrhosis of the liver, toxic hepatitis) Acute } \\
\text { and chronic radiation sickness The metabolism of monoamine in light Uremia }\end{array}$ \\
\hline Hydrogen $\left(\mathrm{H}_{2}\right)$ & $\begin{array}{c}\text { Diseases of bodies of digestion (digestive disorders of infants Gastrointestinal Disorders } \\
\text { anaerobic bacteria in the large intestine Malabsorption hydrocarbons) }\end{array}$ \\
\hline Hydrogen Peroxide $\mathrm{H}_{2} \mathrm{O}_{2}$ & $\begin{array}{c}\text { Respiratory diseases (asthma, chronic obstructive pulmonary disease (COPD), lung cancer, } \\
\text { weakened respiratory lung function, etc.) The acute and chronic radiation sickness Diabetes }\end{array}$ \\
\hline Methane & Diseases of the central nervous system Lung and breast cancer \\
\hline Acetone $\mathrm{C}_{6} \mathrm{H}_{6} \mathrm{O}$ & Diabetes \\
\hline Ethanol & $\begin{array}{c}\text { Alcoholism, the function of the pancreas in acute pancreatitis and execute-destructive } \\
\text { dietary and severe balance failure at lung cancer Diabetes Chronic liver disease }\end{array}$ \\
\hline
\end{tabular}




\begin{tabular}{|c|c|}
\hline Isotopic modification & $\begin{array}{c}\text { Infection with the bacterium Helicobacter pylori passage of food through the gastrointestinal } \\
\text { tract the overgrowth of bacteria lactose Digestion pancreatic Dysfunction Malabsorption } \\
\text { liver dysfunction, including cirrhosis the metabolism of bile glucose metabolism }\end{array}$ \\
\hline Vapors of urine & Gastroenterology \\
\hline Pentane and its Derivatives & $\begin{array}{c}\text { Breath and lung cancer. Acute myocardial infarction Heart titrant rejection Rheumatic } \\
\text { arthritis The exacerbation of asthma }\end{array}$ \\
\hline Alkanes (hexane, etc.) & Lung cancer Tuberculosis \\
\hline $\begin{array}{l}\text { Dimethyl and carbonyl } \\
\text { sulfides }\end{array}$ & $\begin{array}{c}\text { Lung cancer Cystic fibrosis Intra- and extraoral halitosis Chronic liver disease } \\
\text { Hypermethioninemia }\end{array}$ \\
\hline Isoprene & Lung cancer Castaic ulcer Heart failure \\
\hline Hydrogen sulfide & Intraoral halitosis \\
\hline $\begin{array}{l}\text { Heptane, xylenes, octane, } \\
\text { ethylbenzene, styrene, } \\
\text { decane, toluene, benzene, } \\
\text { gaseous aldehyde and } \\
\text { formaldehyde }\end{array}$ & Lung cancer \\
\hline
\end{tabular}

Table 1: Gases as well as Exhalation and Diagnostic Significance.

Note that scientists have grown interested recently to detecting volatile organic compounds (VOCs) for noninvasive diabetes management. According to the World Health Organization, currently there are around 450 million peoples suffering from diabetes in the world, and this number could potentially reach 700 million by 2045 . Human exhaled breath contains thousands of different VOCs derived from the body's metabolic processes. In patients with diabetes mellitus, the body produces excess amounts of ketones such as acetone because the body uses fats instead of glucose to produce energy, which is then exhaled during respiration. Endogenous acetone is produced in the liver primarily through ketogenesis [23]. In certain cases, such as fasting, exercising and being diabetic, the liver produces ketones to act as an additional energy source, which is then metabolized into acetone and other ketone bodies. Using breath analysis techniques, acetone concentrations in the exhaled breath have been shown to correlate with the acetone concentrations in the blood as well as with other ketones such as beta-hydroxybutyrate.

Measurement of breath acetone may provide better diagnostic control of a patient's diabetic condition than using blood glucose alone [24]. At the same time, the detection of the concentration of acetone in the exhaled air can be carried out in a quick and acceptable way for the patient, alternative to the traditional methods for determining glucose in the blood. Many diabetic patients today have to check their blood sugar several times a day, which requires frequent and repeated pricking of their fingers, which is painful and unsafe. It has been established that glucose is also detected in the analysis of tears, saliva, and urine, but their corresponding meters at the commercial level are not yet available to patients.
So, acetone is considered today as the main breath biomarker for metabolic (diabetes) conditions in the bloodstream. It is found that the acetone concentration in exhaled breath of healthy people is ranged between 0.3 and 1. 0. ppm. Diabetes is one of the factors that may cause a change in breath acetone levels. Age, lifestyle, profession, and consuming ketogenic diet influenced breath acetone concentration and increase its concentration. Patients with typical symptoms of diabetes (polyuria, polydipsia and unexplained weight loss) have a high blood glucose concentration. Apart from hyperglycemia, hypoglycemia would damage the human body as well. Clinically, hypoglycemia is determined as a condition where the blood glucose concentration is lower. For elderly patients, the risk coefficient of hypoglycemia is higher. The incidence of hypoglycemia at night is relatively high, and it is difficult to monitor it with traditional blood glucose detection methods. Strict blood glucose control is also likely to increase the risk of hypoglycemia. Therefore, continuous glucose monitoring in diabetics may be of more clinical application value and more in line with market trends [25].

Measurement of the concentration of acetone in breath is necessary. Techniques such as gas chromatography coupled to mass spectrometry, solid-phase microextraction, high-performance liquid chromatography, selected ion flow tube mass spectrometry, and liquid chromatography-mass spectrometry for the detection of different gases. Sensors can be easy prepared by several who have provided a highly selective analysis of VOCs in the breath [26]. Although mentioned above analytical methods are very sensitive and selective for diagnosis of diabetes mellitus, they are expensive, non-portable, and cannot be used out of hospitals. 
Note again, that metal oxides doped with semiconducting CNTs are escellent chemical sensing transducers owing to their exceptionally large charge carrier mobility (about 80 $000 \mathrm{~cm} 2 \mathrm{~V} / \mathrm{s}$ ) and their nanoscale diameter. In contrast, the electron mobility of metal oxide thin films is three to four orders of magnitude smaller than the mobility of SWCNTs or MWCNTs. Carbon nanomaterial enhancement of gas sensor performance can be due to its direct interaction with the gas analysts. Large attention is given in the literature to sensors made from metal oxides doped with CNTs having high sensitivity and other excellent characteristics (see, for example, [5,7,27]). But properties of SWCNTs and gas sensors based on them did not consider earlier by us (see below).

\section{SWCNTs Gas Sensors with Metal Nanoparticles and Metal Oxides}

Metal nanoparticle (NP) /SWCNT gas were showed the sensitivity (response) to $\mathrm{NH}_{3}, \mathrm{NO}_{2}, \mathrm{H}_{2}$, and $\mathrm{H}_{2} \mathrm{~S}$ gases. A metal NP with a lower work function can donate many electrons into the valence band of SWCNTs due to the smaller potential barrier. Zanolli, et al. [28] investigated the sensing mechanism of gold-decorated CNTs by experimentally measuring the change of the resistance $\mathrm{R}$ of this material exposed to different gases $\left(\mathrm{NO}_{2}, \mathrm{CO}, \mathrm{C}_{6} \mathrm{H}_{6}\right)$ and calculated the shift in Fermi level upon exposure of each gas. CNTs were first treated with 02 plasma to create oxygen defects for the purpose of trapping and clustering Au atoms during a thermal evaporation procedure. The Fermi level in the CNT/oxygen defect/Au cluster system was calculated when $\mathrm{C}_{6} \mathrm{H}_{6}, \mathrm{CO}$, or $\mathrm{NO}_{2}$ gas molecules were contacted the cluster surface. The Fermi level is increased in the case of $\mathrm{C} 6 \mathrm{H} 6$ and decreased in the case of $\mathrm{NO}_{2}$. For this system, carbon monoxide did not shift the Fermi level. In the chemiresistor measurements, $\mathrm{NO}_{2}$ exposure caused a large increase in R. C6H6 exposure did not cause a significant change in $\mathrm{R}$, carbon monoxide exposure shows a small increase in R owing to its large binding energy to gold. The sensitivity and selectivity of metal NP receptors can be tailored to specific gases by controlling the size and elemental identity. Penza, et al. [29] investigated the effect of different gold nanocluster sizes sputtered on SWCNTs toward different gases. The sizes of gold nanoclusters chosen were 2.5, 5, and $10 \mathrm{~nm}$. Pd had the largest sensitivity toward CO2. As the affinity gold and sulfur forms Au@S bonds, Au NP/ CNTs have been sensitivity to $\mathrm{H} 2 \mathrm{~S}$ down to $3 \mathrm{ppb}_{2} \mathrm{~S}$ [30]. $\mathrm{Au}$ nanowell (NW)/SWCNTs showed superior sensitivity to low concentrations of H2S compared with Au NP/SWCNT material. To show that this material could be applied to $\mathrm{H}_{2} \mathrm{~S}$ sensing in breath, $\mathrm{H}_{2} \mathrm{~S}$ was successfully detected in an catalytically human breath background of $4 \% \mathrm{CO}_{2}, 20 \% \mathrm{O}_{2}$, and saturated "flavor" vapors.

Note that palladium is is active toward $\mathrm{H} @ \mathrm{H}$ bond dissociation and is significantly cheaper than platinum
[30]. These same properties make Pd NPs excellent $\mathrm{H}_{2}$ sensor receptors. Mubeen, et al. prepared a $\mathrm{H}_{2}$ sensor based on SWCNT networks non-covalently decorated with Pd NPs through electrodeposition [31]. Lundstrçm, et al. [32] proposed that $\mathrm{H}_{2}$ gas molecules adsorbed in air were dissociated into two adsorbed hydrogen atoms on the surface of Pd NPs. In the presence of $\mathrm{O}_{2}$, adsorbed $\mathrm{H}$ atoms can react with $\mathrm{O}_{2}$ molecules to produce water molecules. Electron donation from the hydrogen molecules leads to an increase in $\mathrm{R}$ proportional to hydrogen concentration. The response of the Pd NPs/ SWCNTs network sensed $\mathrm{H}_{2}$ was down to $30 \mathrm{ppm}$. Abdelhalim, et al. investigated the role metal identity played toward gas sensitivity by evaporating $\mathrm{Au}, \mathrm{Ag}$, and Pd NPs of the same size on CNT films and testing their responses toward four gas molecules $\left(\mathrm{NH}_{3}, \mathrm{CO}, \mathrm{CO}_{2}\right.$, and ethanol) [33]. Au/CNT films showed the largest responses toward $\mathrm{NH}_{3}, \mathrm{CO}$, and ethanol, whereas Pd had the largest sensitivity toward $\mathrm{CO}_{2}$. Due to the affinity gold and sulfur have to formAu@S bonds, Au NP/CNTs have been used to sense $\mathrm{H}_{2} \mathrm{~S}$ up to down to $3 \mathrm{ppb} \mathrm{H}_{2} \mathrm{~S}$ [34] and shown a linear chemiresistor response toward $\mathrm{H}_{2} \mathrm{~S}$ for a dynamic range between 0.2 and $1 \mathrm{ppm}$. Au NW/SWCNTs showed superior sensitivity to low concentrations of $\mathrm{H}_{2} \mathrm{~S}$ compared with $\mathrm{Au}$ NP/SWCNT material. $\mathrm{H}_{2} \mathrm{~S}$ was successfully detected in an expected human breath background of $4 \% \mathrm{CO}_{2}, 20 \% \mathrm{O}_{2}$, and saturated "flavor" vapors [30]. These same properties make Pd NPs excellent $\mathrm{H}_{2}$ sensor receptors. The SWCNT-Cl defectPd NP material showed the best sensitivity toward $\mathrm{H}_{2}$, with a LOD down to $10 \mathrm{ppm}$ [35].

Gong, et al. showed that the incorporation of SWCNTs into a sol-gel-prepared $\mathrm{SnO}_{2}$ film could amplify the sensitivity of $\mathrm{SnO}_{2}$ toward $\mathrm{H}_{2}$ [36]. Quantum effects dominate the sensing mechanism of MO/CNT sensors. In the case of a $\mathrm{SnO}_{2} / \mathrm{SWCNT}$ composite, an $\mathrm{n} / \mathrm{p}$ junction is created between the n-type oxide and the p-type s-SWCNTs. Upon exposure to $\mathrm{H}_{2}$, the potential barrier between the $\mathrm{SnO}_{2}$ grain boundaries is lowered. Indium tin oxide (ITO) NPs with SWCNT can sense $\mathrm{NH}_{3}$ with a limit of detection (LOD) of $13 \mathrm{ppb}$ [37]. ITO has $\mathrm{p}$ type conductivity at low concentrations of $\mathrm{NH}_{3}$ and humidity; however, at high levels of humidity, it switched to an n-type semiconductor through the whole compensation effect of water. Adsorption of $\mathrm{H}_{2} \mathrm{~S}$ molecules on the surface of the $\mathrm{SnO}_{2}$ colloid quantum dots (CQDs) results a sensor response toward $\mathrm{H}_{2} \mathrm{~S}$ down to $3.3 \mathrm{ppm}$. In addition, this composite showed selectivity toward $\mathrm{H}_{2} \mathrm{~S}$ when compared with the responses of $\mathrm{NO}_{2}, \mathrm{NH}_{3}$, and $\mathrm{SO}_{2}$. The $\mathrm{Co}_{3} \mathrm{O}_{4} \mathrm{NPs}$ with 4-8 $\mathrm{nm}$ in diameter can be served as CO receptors, achieving sensitivity down to $5 \mathrm{ppm}$.

Thestability of the receptor'sattachment to the transducer is crucial for a reproducible sensor response. In addition, close association between the receptor and transducer is more likely to lead to higher electron delocalization. 
The titanium oxide NPs / SWCNT was sensitive to acetone vapors down to $400 \mathrm{ppb}$ under UV-light. The photo induced electrons after electron/hole pair generation in the $\mathrm{TiO}_{2}$ layer are injected into the p-type SWCNT, causing a decrease in conductance and lower current. Acetone adsorption onto $\mathrm{TiO}_{2}$ /SWCNT prevents electron/ hole recombination; thus causing a detectable drop in conductance. The $\operatorname{In}_{2} \mathrm{O}_{3} /$ SWCNT composite have a greater response towards ethanol than acetone owing to the dissociative adsorption of ethanol on the surface of (111) $\operatorname{In}_{2} \mathrm{O}_{3}$ [38].

Short summary of CNT-based sensors of common breath biomarkers is given below in Table 2 .

\begin{tabular}{|c|c|c|c|c|}
\hline Composite & Detected gas & LOD [ppm] & Dynamic range [ppm] & Ref \\
\hline Pd NP/SWCNT & $\mathrm{H}_{2}$ & 100 & $100-1000$ & [31] \\
\hline Pd NP/SWCNT & $\mathrm{H}_{2}$ & 30 & $30-10000$ & [39] \\
\hline Au NP/SWCNT & $\mathrm{H}_{2} \mathrm{~S}$ & 0.003 & $0.02-1$ & {$[34]$} \\
\hline $\mathrm{Au}$ NW/SWCNT & $\mathrm{H}_{2} \mathrm{~S}$ & 0.005 & $0.005-0.5$ & [41] \\
\hline Ag NC/MWCNT & $\mathrm{NH}_{3}$ & 10 & $10-10000$ & {$[40]$} \\
\hline SnO2 /SWCNT & $\mathrm{H}_{2}$ & 300 & $300-1500$ & [36] \\
\hline TiO2 /ox-SWCNT & acetone & 0.4 & $2-20$ & {$[41]$} \\
\hline ITO NPs/SWCNT & $\mathrm{NH}_{3}$ & 0.013 & $1-20$ & {$[37]$} \\
\hline Co304 / MWCNT & $\mathrm{CO}$ & 5 & $10-700$ & {$[42]$} \\
\hline In203 /ox-SWCNT & ethanol & 2.5 & $2.5-15$ & [38] \\
\hline $\begin{array}{c}\text { SnO2 QDs / } \\
\text { MWCNT }\end{array}$ & $\mathrm{H}_{2} \mathrm{~S}$ & 0.043 & $3.3-100$ & {$[43]$} \\
\hline CuO/ox-SWCNT & ethanol & 2 & $2-11$ & {$[44]$} \\
\hline
\end{tabular}

Table 2: Summary of CNT-based sensors of common breath biomarkers.

Rather than detecting a single chemical component at a much higher sensitivity to others, the CNT array (e-nose) approach provides a "fingerprint" for a given compound. Such analyses as linear discriminant analysis (LDA) or principal component analysis (PCA) are commonly used to provide a reproducible detection result from the array output [45]. Kubert, et al. [46] studied the use of DNA-functionalized SWCNTs as the sensing element in FET devices for VOC differentiation. Chatterjee, et al. [47] replaced DNA with a series of different surfactants to create a chemiresistor array of surfactant-functionalized MWCNTs. An array of these sensors was able to differentiate toluene, chloroform, acetone, ethanol, methanol, and water by using PCA. Haick and co-workers successfully applied the array approach toward discriminating the simulated breath patterns of a healthy subject versus a diseased subject $[48,49]$. The breath investigations of samples of healthy patients and patients with lung cancer were established 15 VOCs that are significant for lung cancer [48]. When a pre-concentration step was used to separate VOCs from humidity, the healthy and cancerous breath patterns could be easily distinguished with PCA. Impedance metric sensing of NH3 is less susceptible to drift because it is an AC measurement [50]. An challenge specific to breath analysis is the confounding effect of high levels of humidity on CNT-based sensors. Therefore, removal or separation of humidity is necessary for most trace breath biomarkers. Methods, such as micro-separation columns, membranes, and the use of silica gel have been also proposed to solve the confounding effect of breath humidity on sensor response. Further clinical research into breath biomarkers and their disease correlations, coupled with advances in CNT-based gas sensors, paves the way toward portable, low power, non-invasive, point-of-care breath analysis devices.

Semiconducting SWCNTs devices can be used as a sensor for chemical nerve agents. Thin-film transistors constructed from random networks of SWCNTs were used to detect dimethyl methylphosphonate (DMMP), a simulant for the chemical warfare nerve agent sarin [51]. The devices consist of a lithographically-patterned SWCNT network that bridges Ti source and drain contacts. The network is grown on the surface of a thermal $\mathrm{SiO}_{2}$ layer, and the Si substrate serves as a common gate electrode.

These results indicate that the electronic detection of nerve agents and potentially other chemical warfare agents is possible with simple-to-fabricate carbon nanotube devices. Researchers have demonstrated that individual semiconducting SWCNT devices produce a large resistance change in response to certain types of gaseous analytes. 
In such sensors, the adsorption of an analyst's molecule with strong electron donor or acceptor properties results in a partial charge transfer between the analysts and the nanotube that changes its electrical resistance. Novak JP, et al. [51] found that the electronic properties of the nanotube networks are strongly affected by the presence of DMMP it readily adsorbs on the SWCNTs, resulting in an effective transfer of negative charge that manifests itself as a shift of the transistor threshold voltage. The molecular adsorption is fully reversible by applying a small positive gate bias that releases the DMMP from the nanotube surface.

The SWCNT-based sensors were reversible and capable of detecting DMMP at sub-ppb concentration levels, and they are intrinsically selective against common interferons. A chemiresistor can detect an exposure to 1 ppb DMMP that was delivered for $3000 \mathrm{~s}$. Sensors are intrinsically selective against interfering signals from hydrocarbon vapors and humidity. Such sensors have detected also $0.1 \mathrm{ppb}$ of $\mathrm{NO}_{2}$, which is superior to current state-of-the-art $\mathrm{NO}_{2}$ sensors by several orders of magnitude. Note that our chemical warfare detectors developed earlier in the framework of the NATO grant are reported in [52].

\section{Acetone Sensors Made from $\mathrm{Sno}_{2}<\mathrm{MWCNT}>$ Nanocomposites}

Metal oxide semiconductor gas sensors widely used today modern microelectronic technology methods, have low cost and high sensitivity. It is shown that chemical gas sensors using various semiconducting metal oxides such as $\mathrm{SnO}_{2}, \mathrm{WO}_{3}, \mathrm{ZnO}, \mathrm{Fe}_{2} \mathrm{O}_{3}$, and $\mathrm{TiO}_{2}$ can be applied for acetone and many other gases detection. Further research in this field is carried out in direction of the dramatically decrease of operating temperature from 300-5000C up to nearroom temperature, understanding the phenomena on the surface of detectors, sensing mechanisms, and improvement of its selectivity to the gas. As electrical resistance in semiconductor metal oxide dramatically changes in the presence of an oxidizing or reducing gases, it is necessary often use only metal oxide-based chemiresistors for many applications. Several factors, such as surface areas, particle size, crystal defects, porous structures, and stoichiometry greatly affect the performance of such sensors. In particular, doping with CNTs is very promising. Some results of the best acetone detectors made of $\mathrm{SnO}_{2}<\mathrm{MWCNT}>$ are shown in Table 3.

\begin{tabular}{|c|c|c|c|}
\hline Sensor & Work Temp & Response (ppm) & Ref. \\
\hline $\mathrm{SnO}_{2}<\mathrm{MWCNT}>$ & 250 & $\begin{array}{c}4.70(0.2) \\
1002(1000)\end{array}$ & {$[5,7,53,54]$} \\
\hline $\mathrm{SnO}_{2}<\mathrm{MWCNT}>$ & 200 & $120(2.5)$ & {$[55]$} \\
\hline
\end{tabular}

Table 3: $\mathrm{SnO}_{2}<$ MWCNT $>$ ACETONE SENSORS.

A heterostructure acetone sensor made from NiOdoped $\mathrm{SnO}_{2}$ hollow nanofilaments with porous structures through the combination of electrospinning technique and calcination procedure was developed [56]. The excellent sensing performances of the proposed sensor were ascribed to its hollow-core structure and $\mathrm{Ni}$ doping. In fact, the presence of heterojunctions formed by the combination of p-type $\mathrm{NiO}$ and n-type $\mathrm{SnO}_{2}$ increased the sensor resistance and sensory responses to acetone vapor. The enhanced acetone sensing can be ascribed to the formation of $p-n$ junction between p-type $\mathrm{NiO}$ and n-type $\mathrm{SnO}_{2}$ grains. The gas sensor based on $\mathrm{NiO}-\mathrm{SnO}_{2}$ nanofibers has a maximum gas response at the operating temperature of $275^{\circ} \mathrm{C}$, while the sensor based on $\mathrm{NiO}$ shows the highest responses at $325^{\circ} \mathrm{C}$. NiO- $\mathrm{SnO}_{2}$ exhibits a better selectivity than $\mathrm{NiO}$, having a preferential response to acetone. Therefore, the $\mathrm{NiO}-\mathrm{SnO}_{2}$ nanofibers could be used for selective acetone detection. Acetone sensors based on $\mathrm{SnO}_{2}$, doped with Eu are reported in $[57,58]$. Work temperature was $280^{\circ} \mathrm{C}$ for such sensors. Y-doped $\mathrm{SnO}_{2}$ nanosensors were developed in [59].

It was shown in Yerevan State University [7] that the functionalized $\mathrm{SnO}_{2}$-MWCNT thick-film structures with $\mathrm{Ru}$ catalyzer leads to a considerable increase in response signal to the VOC gases. Structures were obtained by hydrothermal synthesis and sol-gel techniques as well as their combination. The choice of corresponding treating conditions and regimes for CNTs functionalization as well as thick film surface modification with Ru catalyst were focused in $[7,53,60]$. The testing of all samples at different operating temperatures in other to compare responses to various considered here target VOCs was carried out.

The largest and sufficiently selective response to acetone vapors $(\mathrm{Ra} / \mathrm{Rg}=1002)$ at their concentration of $1000 \mathrm{ppm}$ is achieved at samples with 1:200 (MWCNT: $\mathrm{SnO}_{2}$ ) mass ratio of the components. The largest response to acetone vapors $(\mathrm{Ra} / \mathrm{Rg}=555,62)$ is fixed for such a set of samples to acetone vapors exposure $1000 \mathrm{ppm}$ at $250^{\circ} \mathrm{C}$ operating temperature. Selective sensitivity of acetone vapors sensors with 1:50 mass ratio of the components appears only at the $300^{\circ} \mathrm{C}$ operating temperature.

As an example, the dependence of the 1:200 sensor response vs acetone vapor concentration at $150^{\circ} \mathrm{C}$ is presented in Figure 3. Note that the gas response increases 
linearly with acetone vapor concentration in its large range. It opens a possibility to realize an easy detector/measurer of the concentration of acetone in the air or exhaled breath gas.

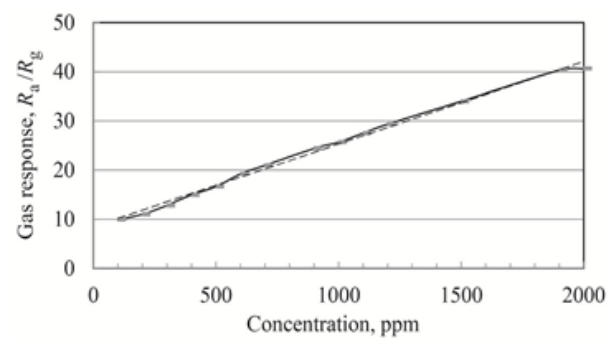

Figure 3: Dependence of the SnO2<MWCNT> sensor response vs acetone vapor concentration.

It is obvious today that the doping of metal oxide with CNTs leads to better sensitivity and lower preheating of the work body of a hybrid sensor. Note that several complicate phenomena processes take place in such functionalized nanocomposites. The full picture is not possible to propose today, but we have to take into account the following: MWCNTs have a huge specific surface area and a nanoscale structure, which exposes a large number of sites at which the gases can react. Detection of various gases can be provided at low temperatures of pre-heating of the work body of a sensor. The electric conductivity of CNTs is much higher in comparison with the conductivity of metal oxides. Therefore, CNTs reduce the resistance of the sensing metal oxide materials and open the possibility for the percolation of charge carriers through the sample. Since a metal oxide film has mainly n-type semiconductor characteristics and MWCNTs have p-type semiconductor characteristics, there are two depletion layers in such hybrid films. Note that the first depletion region is located at the metal oxide surface and the second one is located in the interface between the metal oxide nanoparticle and the MWCNTs. Formation of Nano channels and heterojunctions leads to enhanced gas sensitivity of such hybridized gas sensors as the decrease in the work function (barrier height) or increase in the conductivity of the metal oxide sensitive layer leads to the improvement in the performance of the gas sensor at low operating temperature.

The response of the prepared sensor toward $1 \mathrm{ppm}$ acetone vapor at $250^{\circ} \mathrm{C}$ was presented in Figure 4 [61]. It is shown that the resistance decreases very sharply after exposure of acetone.
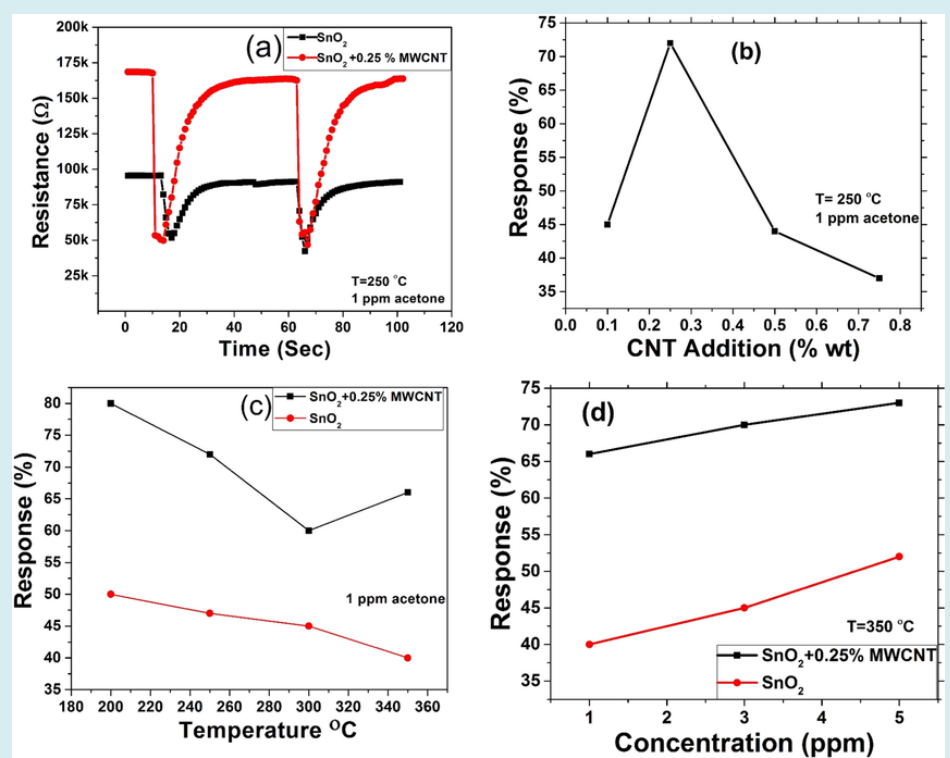

Figure 4: (a) The response of $\mathrm{SnO}_{2}$ and $\mathrm{SnO}_{2}<0.25 \%$ MWCNT> sensors in $1 \mathrm{ppm}$ acetone at $250^{\circ} \mathrm{C}$. (b) The response of $\mathrm{SnO}_{2}$ sensor in $1 \mathrm{ppm}$ acetone for different CNT loadings at $250^{\circ} \mathrm{C}$. (c) The response of $\mathrm{SnO}_{2}$ and $\mathrm{SnO}_{2}<0.25 \% \mathrm{MWCNT}>$ nanocomposite sensors in $1 \mathrm{ppm}$ acetone at different temperatures. (d) The response of $\mathrm{SnO}_{2}$ and $\mathrm{SnO}_{2}<0.25 \% \mathrm{MWCNT}>$ sensors in different concentrations of acetone at $350^{\circ} \mathrm{C}[61]$.

The addition of MWCNTs improves significantly the sensitivity of SnO2. The sensitivity study was carried out for different concentrations of MWCNT to get the highest response as shown in Figure 4b. It is to be noted that the highest sensitivity was achieved for $\mathrm{SnO}_{2}$ loaded in $0.25 \%$ MWCNTs. The over-addition of MWCNTs in the composite decreases the resistance of the sensor sharply. For overaddition of MWCNTs, the increasing number of electrons in 
the grain boundary reduces the resistance and increase the sensitivity of the sensors. The response toward acetone vapor was jumped to $72 \%$ after the addition of $0.25 \%$ MWCNT. The response of sensors made from pure nanocrystalline $\mathrm{SnO}_{2}$ and $\mathrm{SnO}_{2}$ loaded in $0.25 \%$ MWCNTs toward $1 \mathrm{ppm}$ acetone for different operating temperatures is shown in Figure 4c. $0.25 \%$ MWCNT loaded $\mathrm{SnO}_{2}$ sensor showed a much better response at the lower temperature. The sub-ppm level acetone sensing at $350^{\circ} \mathrm{C}$ is presented in Figure $4 \mathrm{~d}$.

Note that nanonsensors to hydrogen dioxide made of $\mathrm{SnO}_{2}<\mathrm{MWCNT}>$ were reported also in $\mathrm{ZnO}<\mathrm{CNT}>$ in [62]. Ahmadnia-Feyzabad, et al. [54] also fabricated multiwall carbon nanotubes 1:200 MWCNT/ $\mathrm{SnO}_{2}$ sensors using the ultrasonic-assisted deposition-precipitation method and they were used for detection of four VOCs, including acetone. Significant enhancement of the sensor selectivity to acetone with respect to gases like toluene and trichloroethylene was observed. Narjinary, et al. [61] developed highly sensitive and stable acetone sensor by using MWCNTs as a substrate for sol-gel prepared nanocrystalline $\mathrm{SnO}_{2}$. It was mentioned that the enhancement in sensing performance was due to the formation of hetero-junction and an increase in adsorption capacity because of the higher surface area of MWCNT.

\section{Non-Invasive Diagnosis of Diabetes}

When analyzing the effects of acetone on diabetic patients, it would probably make sense to start from the concentration of acetone $1 \mathrm{ppm}$. Most diabetics are at a relatively early stage of the disease (the concentration of released acetone is $1-2 \mathrm{ppm}$ ), basically they are not under the daily supervision of doctors. A miniature and easy transportable glucose (sugar) meter is needed for such patients. The dependence of the response of the gas sensor on the concentration of acetone for a healthy and sick person is shown in Figure 5 [26].

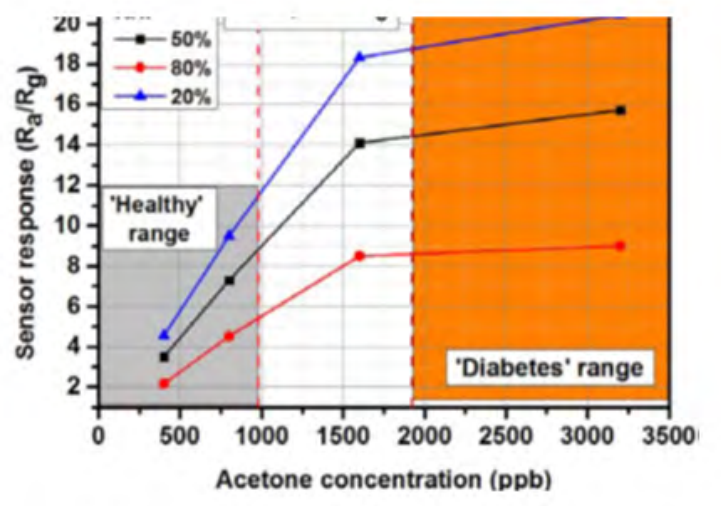

Figure 5: "Healthy" and "diabetic" regions in the sensor of silicon-doped WO3 acetone [26].
The analysis of the acetone influence for diabetic subjects has the sense to make starting $1 \mathrm{ppm}$. For its implementation, it is necessary to have, for example, such a sensor with a high sensitivity to acetone of the type as measured by Dr. A. Sayunts at YSU in the concentration range of 1-12 ppm on our sensor made of $\mathrm{SnO}_{2}<$ MWCNT $>$ (Figure 6).

We manufactured earlier semiconductor monitors, including those using Arduino Nano processors [63]. Note that for the implementation of a non-invasive monitor of acetone with a tube, such as shown in Figure 2, it is additionally necessary to develop the latter with a special mouthpiece or a drier of the patient's exhaled air. High humidity of exhaled air created often corresponding higher requirements to sensors. Therefore, it is necessary to develop a pre-concentrator to its. The pre-concentration technique is well known in chromatography where the separation column is filled with adsorbent molecules. The same mechanism is mostly applied for pre-concentrators to exhaled biomarkers. Two-step pre-concentration in order to reduce the humidity level in exhaled samples is preferable today.

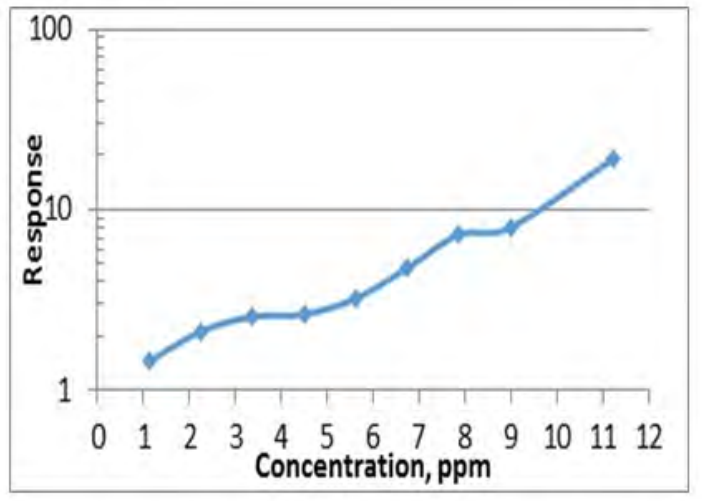

Figure 6: Dependence of response of our sensor made of $\mathrm{SnO}_{2}<\mathrm{MWCNT}>$ on the concentration of acetone.

\section{Carbon Nanotubes based Biosensors}

CNTs based biosensors can be used in ultra-sensitive and ultra-fast biosensing systems. The basic and some new developed synthetic methods of CNTs are presented in [64]. Note that the concept of CNT-based biosensor was derived from the description of the enzyme electrode by Clark [65]. In general, the CNT-based biosensor includes two parts: biological sensitive element and transducer. The CNT functionalized with biomolecules or bioreceptors, such as proteins, cell receptors, enzymes, antibodies, microorganisms, or even whole biological tissues, which are working as the biological sensitive element [66-68]. The role of transducer is to convert the concentration of analysts to other physical signals, such as currents, absorbance, or mass. 
According to the interactions between analysts and the biological sensitive materials, CNT-based biosensors will be separated into two categories: chemical and physical. Among of them, the CNTs-field effect transistors have superior properties.

The hollow structure of CNTs is good for the adsorption of enzymes. Therefore, CNTs in amperometric CNTs-based biosensors are always used to functionalize with enzymes to generate the enzyme CNT electrodes or to modify the surface of electrodes. CNTs in the CNTFET biosensor configured as FETs offer the advantages of possible biocompatibility, size compatibility, and sensitivity toward minute electrical perturbations for the detection of biological species [69]. They are also low-cost, low-noise and portable [70]. In addition, the effective detect area can be made into the size of a single biomolecules or virus. Because of these unique characteristics, CNTFET biosensor has been widely used in the field of biology, such as protein, glucose, enzyme, antigen and antibody molecules, DNA molecules, bacteria and hormone [71,72]. In CNTFET biosensor, the preparation of metal electrodes as source and drain electrode are prepared on the surface of silicon substrate coated with silicon dioxide insulating layer. The connection of specific CNTs between the two electrodes is acted as conductive channel, and introducing a gate electrode. The CNTs were synthesized by CVD and the distance between the two electrodes is very small. The specific antibodies can be coated with CNTs, specificity adsorption between antigen and antibody could generate an electric signal that is observed and recorded $[69,73]$. According to the different reactants, CNTFETs are divided into different types of FET including enzyme FET, immune FET, organization FET, cell FET, and DNAFET. Over the past decade, many groups have brought significant contributions in the development of CNTFET biosensors. For instance, Star, et al. [74] prepared nanoscale FET devices with SWCNTs as the conducting channel for the electronic detection of specific protein binding.

Functionalization of CNTs with other nanomaterials, such as polymer, proteins, DNA, enzyme to improve their dispersibility and compatibility with the target biological species [75]. Functionalized CNTs have many improved characteristics, such as large edge plane, high surface activity, high catalytic efficiency and more functional groups. Using the functionalized CNTs can improve the fixed efficiency of biological recognition of molecules (enzymes, DNA, antigen/ antibody, etc.) in biosensors (Table 2 [65]). Compared with the conventional solid-state carbon biosensors, the biosensors made of functionalized CNTs have higher sensitivity, faster response, and wider detection range. The roles of functionalized CNTs and technologies how to prepare the functionalized CNTs are discussed in very interesting and comprehensive review [65].
Note again that investigations of CNTs look like the most exciting areas in current materials sciences, and the development of CNTs for biomolecule detection is particularly important for bioengineering and biomedical applications. Novel nanotechnologies such as nanoimprint lithography and soft lithography are helpful. Both chemical and physical properties of functionalized CNTs strongly depend on the ambient conditions, such as temperature and $\mathrm{pH}$. Some studies have indicated that the sensitivity and the detection limits is significantly enhanced using nanocomposite materials combine with CNTs and metal $\mathrm{Au}$, $\mathrm{Pt}$, etc.) for biosensor. With the sustainable development of new nanomaterials combined with CNTs, the characterization of these new materials at the molecular level is essential and a key scientific challenge. In parallel with experimental studies, molecular modeling must be further developed as a tool to predict the performance of new materials for given biomolecules. Such computational methods will enable a quick evaluation of new materials. Clearly, the further development of CNT-based biosensors will allow to fabric of such new micro- /nano-devices as bionanosensors.

Recent developments of novel nanosensors offer promising approaches for improved clinical diagnostics and treatments, with increasing interest in nanomaterialsbased biosensors [76-89]. A sensor can include antibodies, aptamers, DNA sequences, molecular imprints, lectins, or synthetic moieties. Various nanoparticles have shown the potential to be highly sensitive and selective, such as metal nanoparticles, quantum dots, nanowires, graphene, graphene quantum dots, and carbon nanotubes that can bind and detect biologically relevant concentrations of a targeting analyst. The use of carbon nanotubes as sensors for biotechnological and biomedical applications is of particular interest [90]. SWCNTs demonstrated long-term stability in vivo [91-95].

The non-photo bleaching, the non-blinking fluorescent emission of SWCNTs allows using them as optical sensors, enabling in situ, label-free, real-time detection with both spatial and temporal resolution [94-96]. Recent studies have demonstrated the detection of proteins using various approaches for surface functionalization, including natural substrates [97-100] and synthetic polymers [94], with the potential to enable long-term continuous monitoring of important biomarkers or to replace costly and timeconsuming laboratory testing. The advantages of SWCNTs for in-vivo and in-vitro biomedical applications such as drug delivery, imaging, and sensing, focusing on protein recognition are investigated. Therefore, the properties of SWCNTs make them excellent candidates for sensing proteins and bio-macromolecules, with optical signal transduction, where advancements in nanotechnology design, synthesis, characterization, and modeling will continue to push forward 
the discovery of new SWCNT-based fluorescent sensors. Other applications of carbon nanotubes in medicine.

Possibilities to use of gas semiconductor detectors for detecting diseases, and, in particular, diabetes, in an organism were discussed above. Note also that detectors made from other metal oxides can serve as analyzers of exhaled (for example, $[101,102])$. So, CNTs an ideal material for the development of a new class of molecular sensors.

Carbon nanotubes (CNTs) are also widely used in dentistry, virology, and cardiology. One of the most active research fields in modern biomedical engineering and clinical practice is the repair and regeneration of hard tissues in the human body such as bone and teeth. Traditional materials that serve as scaffolds in clinical applications include naturally-derived collagen, chitosan, and different synthetic polymers. Of course, it is desirable for the scaffold to be biocompatible and able to control the proliferation and differentiation of cells into the required lineage and structure. The good mechanical strength, flexibility, and lightweight make CNTs ideal materials for use as reinforcement of engineered composites. Today CNTs are used in functional scaffolds for repairing and regenerative purposes [103].

Inorganic composite-based MWCNT hybrid membranes coated with copper(I) oxide, titanium(IV) oxide, and iron(III) oxide nanoparticles were investigated in the removal of viruses (bacteriophages) from contaminated water and used as virus adsorbents [104].

Injectable polymer/CNT composites are using today for enhancing cardiomyocyte proliferation and function [105], and cardiac differentiation of stem cells [106]. Electrically conductive CNTs can be used in composite scaffolds as synthetic cell culture platforms for enhanced differentiation of human mesenchymal stem cells (hMSCs). Through analysis of fiber morphology, elastic modulus and conductivity, it was established that scaffold properties are affected by the inclusion of CNTs and can be tailored for specific applications. CNTs-based scaffolds have been recently found to support the in vitro growth of cardiac cells: in particular, their ability to improve cardiomyocytes proliferation, maturation, and electrical behavior are making CNTs extremely attractive for the development and exploitation of interfaces able to impact cardiac cells physiology and function.

CNTs are used now as new nanocarriers for drug delivery. Researchers have recently applied CNTs to diagnose and treat cancers such as lung, breast, prostate, liver, colon, etc [107]. Besides, quantum dots, gold, and magnetic nanoparticles were a series of nanomaterials that could be utilized to detect cancers [108]. The methods of chemotherapy, radiation therapy, and various medications are used for the detection of different cancers (for example, lung cancer [109]). These methods were not highly effective due to the non-targeted and damaging of healthy tissues such as hair follicles. Based on these approaches, damage in the cell cycle, break in the double strands of DNA, inflammatory responses, tissue fibrosis, etc., will have occurred. On the other hand, there were a series of treatment obstacles; low stability, solid solubility in water, and cell resistance to treatment in the chemotherapy method.

Tumor-targeting has many difficulties even with using the specific antibodies to bind to cancer cells; pulmonary tumors are among the invincible types of cancer, on which the researchers work to solve this issue. In fact, CNTs are made in five ways, which are described as arc discharge, laser ablation, chemical vapor deposition, flame synthesis, and silane solution methods. Also, CNTs are purified in three ways as air oxidation, sonication, and acid refluxing. On the other hand, the CNTs are a fascinating substance that can be employed to bind proteins, peptides, nucleic acids, and various drugs. Furthermore, CNTs have a high potential for drug delivery due to their tubular and fiberlike structure. The usable techniques to evaluate the CNTs and drugs with each other were collected as transmission electron microscopy (TEM), scanning electron microscopy (SEM), Raman spectroscopy; Fourier transforms infrared spectroscopy (FTIR), and X-ray diffraction (XRD), etc.

Consider below the pulmonary toxicity assessment of CNTs. CNTs could quickly enter the lungs through the respiratory tract and then rapidly enter and affect the nervous, lymphatic, and circulatory systems, leading to toxic effects [110]. The main reasons for these toxic effects can be durability, the amount of residual oxygen reactive metal, and size. By removing the residual metals and selecting appropriate dimensions, the CNTs can be safe in drug transmission. The smaller sizes were with less toxicity; furthermore, the concentration of metal impurities such as iron did not contribute to toxicity [111]. Indeed, the greater the curvature, the less damage occurred to the cells. Due to the high structural similarity of CNTs with asbestos, which is usually used, similar physiological effects on the human bronchial epithelial cells are shown. In humans exposed to the CNTs, they could induce lung and pleural lesions, inflammation, pleural fibrosis, and lung tumors. The stiffness, hardness, length, width, and CNT longevity are five factors that could induce a harmful effect.

The too-lowest dose of MWCNTs could induce pulmonary fibrosis. Also, MWCNTs, like asbestos, could alter the expression of several genes and cell survival and proliferation [112]. The CNT produced the least toxicity compare with asbestos. On the other side, functional CNT showed less toxicity with higher activity toward CNT without 


\section{Physical Science \& Biophysics Journal}

functionalization. The safe applied dose of CNTs was not yet finally determined [113]. Also, researchers can reduce (rule) the toxic effects by choosing the appropriate dimensions (shorter length and higher width), more curved nanotubes, and using the functionalized form [114]. Moreover, the MWCNT was used more efficiently due to less toxicity toward SWCNT. On the other side, there were significant contrasts in using the nanotubes which induced tumor growth and tumor suppressor protein.

Using CNTs in lung cancer treatment is very promising. Generally, lung cancer's clinical manifestations include fatigue, coughing, wheezing, pain in the chest, the brevity of breath, swallowing hardness, anxiety, and yellow fingers. Also, a lung cancer diagnosis is possible with helping 4 methods with the names of radiological, non-radiological imaging such as MRI, endoscopic, and biochemical methods [115]. As usual, diagnosis, type, and degree of lung cancer are performed by CNTs scan imaging [116,117]. But, unfortunately, too low-dose CNT scans may bring falsepositive answers about having lung cancer [118]. Today, the biomarkers of both protein and genetic modifications are known for lung cancer.

Numerous biosensors were studied to bind to these biomarkers for non-invasive detection [119]. The sensor array of CNTs has demonstrated a discrepancy between the healthy and the patient respiratory sample in the volatile organic components (VOC). Therefore, the detection of VOCs and tumor markers by breath analysis with helping CNT is a modern and studied method. [20,21,120]. The sensors identify different biomarkers due to the solubility, polarity, and chemical associations, especially for tuberculosis disease [121]. The design of an electronic nose with CNTs to delete the VOC of lung cancer patients was an inexpensive and rapid method. Water, methanol, isopropanol, ethanol, acetone, 2-butanone, and propanol were found as polar vapors lung cancer biomarkers. The CNTs, doped with platinum, can detect styrene and benzene vapors that existed in the exhale of lung cancer patients. This sensitivity was very low in natural nanotubes.

SWCNTs decorated with $\mathrm{Pd}, \mathrm{Pt}, \mathrm{Ru}$, or Rh elements could also be used to detect toluene gas as an indicator of lung cancer. Research, conducted in [122], stated that a biosensor created by CNT covered with Rh catalyzer can distinguish and absorb $\mathrm{C}_{6} \mathrm{H}_{7} \mathrm{~N}$, and $\mathrm{C}_{6} \mathrm{H}_{6}$ in the exhaled air of lung cancer patients [120]. Another scheme used to enhance lung cancer detection was preparing a combination of SWCNT and chitosan [123]. Due to the differences in nicotinic acetylcholine receptors in normal and small cells of lung cancer, the nanotube-based electrode sensor for the quantitative electrophysiological monitoring of a no adherent cell has been demonstrated [124].

\section{Conclusion}

Excellent physical properties of CNTs are using for the manufacturing of many electronic devices. Single wall CNTs and gas sensors based on them are also promising for the detection of many important gases including gases exhaled by the organism. The treatment with CNT is much more effective than the traditional treatments. Using the functionalization, nanotubes with a longer length, more width, and greater curvature partially can be make with lower toxicity. CNTs can be used for effective drug delivery and toxicities of tumor cells without the damage of healthy ones.

The paper presents and discusses also the work carried out on non-invasive metal oxide sensors (chemiresistors) for acetone exhaled by diabetics. Such sensors are manufactured using the methods of modern microelectronic technology. The response of chemiresistors made of $\mathrm{SnO}_{2}$ doped with MWCNT was measured at a concentration of acetone released from 1 to $12 \mathrm{ppm}$, typical for diabetics. Carbon nanotubes (CNTs) are also widely used in dentistry, virology, and cardiology.

Application of CNT-based sensors to breath analysis, properties of the SWCNTs gas sensors with metal nanoparticles and metal oxides and CNTs biosensors are reviewed in this paper.

\section{References}

1. Geier ML, Prabhumirashi PL, McMorrow JJ, Xu W, Seo JW, et al. (2013) Subnanowatt Carbon Nanotube Complementary Logic Enabled by Threshold Voltage Control. Nano Lett 13(10): 4810-4816.

2. Zou J, Zhang K, Li J, Zhao Y, Wang Y, et al. (2015) Carbon nanotube driver circuit for $6 \times 6$ organic light emitting diode display. Sci Rep 5: 11755.

3. Cao Z, Wei BBQ (2013) A perspective: carbon nanotube macro-films for energy storage. Energy Environ Sci 6: 3183-3170.

4. Shikata Sh (2016) Single crystal diamond wafers for high power electronics. Diamond and Related Materials 65: 168-175.

5. Aroutiounian VM (2018) Properties of hydrogen peroxide sensors made from nanocrystalline materials. Sens Transducers 223(7): 9-21.

6. Aroutiounian VM, Adamyan AZ, Khachaturyan EA, Adamyan ZN, Hernadi K, et al. (2013) Study of the surface-ruthenated SnO2/MWCNTs nanocomposite thick-film gas sensors Sens. Actuator B 177: 308-315. 
7. Aroutiounian VM (2018) Properties of hydrogen peroxide sensors made from nanocrystalline materials. Sensors \& Transducers 223(7): 9-21.

8. Adamyan ZN, Sayunts AG, Khachatryan EA, Aroutiounian VM (2021) Tin Oxide/Carbon Nanotube Nanocomposite Sensors for Some Toxic VOCs Detection. South Florida Journal of Development Miami 2(1): 1067-1093.

9. Aroutiounian VM (2018) Hydrogen peroxide solid-state sensors. Armenian Journal of Physics 11(1): 39-60.

10. Harris P (1999) Carbon nanotubes and related structures. Cambridge University Press, USA, pp: 279.

11. Hopley EL, Salmasi DM, Kalaskar AM, Seifalian EL Hopley S, et al. (2014) Carbon Nanotubes Leading The Way Forward in New Generation 3D Tissue Engineering. Biotechnology Advances 32(5): 1000-1014.

12. Masikini M, Chowdhury M, Nemraou O (2020) Application in Exhaled Breath Acetone Chemiresistive Sensors. J Electrochemical Society 167: 037537.

13. Yang N, Chen X, Ren T, Zhang P, Yang D (2015) Carbon nanotube based biosensors. Sens Actuators B 207: 690715.

14. Szabó A, Perri C, Csató A, Giordano G, Vuono D, et al. (2010) Synthesis Methods of Carbon Nanotubes and Related Materials 3(5): 3092-3140.

15. Berki P, Nemeth Z, Reti B, Berkesi O, Margez A, et al. (2013) Preparation and characterization of multiwalled carbon nanotube $/ \operatorname{In}_{2} \mathrm{O}_{3}$ composites. Carbon 60: 266272.

16. Aroutiounian VM (2012) Hydrogen sensors. In: $2^{\text {nd }}$ (Edn.), Dekker Encyclopedia of Nanoscience and Nanotechnol, Taylor and Francis, New York, USA.

17. Aroutiounian VM (2013) Porous silicon gas sensors. Chapter 12, Woodhead Publishing Series in Electronic and Optical Materials 38: 408-420.

18. Arouriounian VM (2007) Metal oxide hydrogen, oxygen, and carbon monoxide sensors for hydrogen setups and cells. Int J Hydrogen Energy 32(9): 1145-1158.

19. Aroutiounian VM (2019) Gas Nanosensors Made from Semiconductor Metal Oxides. Journal of Contemporary Physics (Armenian Academy of Sciences) 54: 356-367.

20. Aroutiounian VM (2020) Microelectronic gas sensors for non-invasive analysis of exhaled gases. J Nanomed Nanotechnol 11(3): 1-7.
21. Aroutiounian VM (2021) On non-invasive measurements of exhaled acetone using metal oxide nanosensors. Journal of Nanomedicine \& Nanotechnology 12(3).

22. Aroutiounian VM (2019) Semiconductor gas sensors detector using Arduino NANO. Biomedical J Sci \& Tech Research 12: 283-287.

23. Dedov II, Shestakova MV (2011) Diabetes mellitus: diagnosis, treatment, prevention. Medical Information Agency, LLC Publishing House.

24. Saasa V, Malwela T, Beukes M, Mokgotho M, Liu Ch-P, et al. (2018) Sensing Technologies for Detection of Acetone in Human Breath for Diabetes Diagnosis and Monitoring. Diagnostics 8(1): 12.

25. Tang L, Chang SJ, Chen CJ, Liu JT (2020) Sensors NonInvasive Blood Glucose Monitoring Technology: A Review. Sensors (Basel) 20(23): 6925-6957.

26. Rydosz A (2018) Sensors for enhanced detection of acetone as a potential tool for non-invasive diabetes monitoring. Sensors 18(7): 2298.

27. Ellis JE, Star A (2016) Carbon Nanotube Based Gas Sensors toward Breath Analysis. Chem Plus Chem 81(12): 1248-1265.

28. Zanolli Z, Leghrib R, Felten A, Pireaux JJ, Llobet E, et al. (2011) Gas sensing with Au-decorated carbon nanotubes. ACS Nano 5(6): 4592-4599.

29. Penza M, Rossi R, Alvisi M, Cassanoa G, Serra E (2009) Functional characterization of carbon nanotube networked films functionalized with tuned loading of $\mathrm{Au}$ nanoclusters for gas sensing applications. Sens Actuators B 140(1): 176-184.

30. Shao M (2011) Palladium-based electrocatalysts for hydrogen oxidation and oxygen reduction reactions. Journal of Power Sources 196(5): 2433-2444.

31. Mubeen S, Zhang T, Yoo B, Deshusses MA, Myung NV (2014) Palladium nanoparticles decorated singlewalled carbon nanotube hydrogen sensor. J Phys Chem C 111(17): 6321-6327.

32. Lundström I, Spetz A, Winquist F, Ackelid U, Sundgren H (1990) Catalytic metals and field-effect devices-a useful combination. Sens Actuators B 1(1-6): 15-20.

33. Abdelhalim A, Abdellah A, Scarpa G, Lugli P (2014) Metallic nanoparticles functionalizing carbon nanotube networks for gas sensing applications. Nanotechnology 25: 055208 . 
34. Mubeen S, Zhang T, Chartuprayoon N, Rheem Y, Mulchandani A, et al. (2015) Sensitive Detection of $\mathrm{H}_{2} \mathrm{~S}$ Using Gold Nanoparticle Decorated Single-Walled Carbon Nanotubes. Analytical chemistry 82(1): 250-257.

35. Goldsmith BR, Coroneus JG, Khalap VR, Kane AA, Weiss GA, et al. (2007) Conductance-controlled point functionalization of single-walled carbon nanotubes. Science 315(5808): 77-81.

36. Gong J, Sun J, Chen Q (2008) Micromachined sol-gel carbon nanotube $/ \mathrm{SnO}_{2}$ nanocomposite hydrogen sensor. Sensors Actuators B 130(2): 829-835.

37. Rigoni F, Drera G, Pagliara S, Goldoni A, Sangaletti L (2014) High sensitivity, moisture selective, ammonia gas sensors based on single-walled carbon nanotubes functionalized with indium tin oxide nanoparticles. Carbon 80: 356-363.

38. Ellis JE, Green U, Sorescu DC, Zhao Y, Star A (2015) Indium oxide-single-walled carbon nanotube composite for ethanol sensing at room temperature. J Phys Chem Lett 6(4): 712-717.

39. Sun Y, Wang HH (2007) High-Performance, flexible hydrogen sensors that use carbon nanotubes decorated with palladium nanoparticles. Adv Mater 19(19): 28182823.

40. Cui S, Pu H, Lu G, Wen G, Mattson EC, et al. (2012) Fast and selective room-temperature ammonia sensors using silver nanocrystal-functionalized carbon nanotubes. ACS Appl Mater Interfaces 4(9): 4898-4904.

41. Ding M, Sorescu DC, Star A (2013) Photoinduced charge transfer and acetone sensitivity of single-walled carbon nanotube-titanium dioxide hybrids. J Am Chem Soc 135(24): 9015-9022.

42. Dang L, Zhang G, Kan K, Lin Y, Bai F, et al. (2014) Heterostructured $\mathrm{Co}_{3} \mathrm{O}_{4} / \mathrm{PEI}-\mathrm{CNTs}$ composite: fabrication, characterization and $\mathrm{CO}$ gas sensors at room temperature. J Mater Chem A 2: 4558-4565.

43. Liu H, Zhang W, Yu H, Gao L, Song Z, et al. (2016) SolutionProcessed Gas Sensors Employing $\mathrm{SnO}_{2}$ Quantum Dot/ MWCNT Nanocomposites. ACS Appl Mater Interfaces 8(1): 840-846.

44. Peng G, Wu S, Ellis JE, Xu X, Yu C, et al. (2016) Singlewalled carbon nanotubes templated $\mathrm{CuO}$ networks for gas sensing. J Mater Chem C 4: 6575-6580.

45. Jurs PC, Bakken GA, McClelland HE (2000) Computational methods for the analysis of chemical sensor array data from volatile analytes. Chem Rev 100(7): 2649-2678.
46. Kubert NJ, Lerner MB, Yodh JS, Preti G, Johnson ATC (2013) Differentiation of complex vapor mixtures using versatile DNA-carbon nanotube chemical sensor arrays. ACS Nano 7(3): 2800-2807.

47. Chatterjee S, Castro M, Feller JF (2015) Tailoring selectivity of sprayed carbon nanotube sensors (CNT) towards volatile organic compounds (VOC) with surfactants. Sens Actuators B 220: 840-849.

48. Peng G, Tisch U, Haick H (2009) Detection of Nonpolar Molecules by Means of Carrier Scattering in Random Networks of Carbon Nanotubes: Toward Diagnosis of Diseases via Breath Samples. Nano Lett 9(4): 1362-1368.

49. Peng G, Trock E, Haick H (2008) Detecting simulated patterns of lung cancer biomarkers by random network of single-walled carbon nanotubes coated with nonpolymeric organic materials. Nano Lett 8(11): 36313635 .

50. Hong HP, Kim JH, Lee CJ, Min NK (2015) In-plane impedancemetric ammonia sensing of solutiondeposited, highly semiconductor-enriched single-wall carbon nanotube submonolayer network gas sensors. Sens Actuators B 220: 27-32.

51. Novak JP, Snow ES, Houseret EJ, Park D, Stepnowski JL, et al. (2003) Nerve agent detection using networks of single-walled carbon nanotubes. Applied physics letters 83(19): 4026-4028.

52. Aroutiounian VM (2018) Semiconductor gas sensors for detection of chemical warfare agents and toxic industrial chemicals. Int Sci J Alternative Energy Ecology 249-251: 38-45.

53. Aroutiounian V, Adamyan Z, Sayunts A, Khachaturyan E, Adamyan A (2014) Comparative Study of VOC Sensors Based on Ruthenated MWCNT/SnO $\mathrm{S}_{2}$ Nanocomposites. Int J Emerging Trends in Science and Technology 1(8): 1309-1319.

54. Ahmadnia-Feyzabad S, Khodadadi AA, Vesali-Naseh M, Mortazavi Y (2012) Highly sensitive and selective sensors to volatile organic compounds using MWCNTs/ $\mathrm{SnO}_{2}$. Sens Actuators B Chem 166-167: 150-155.

55. Salehi S, Nikan E, Khodadadi AA, Mortazavi Y (2014) Highly sensitive carbon nanotubes-SnO2 nanocomposite sensor for acetone detection in diabetes mellitus breath. Sens Actuators B Chem 205: 261-267.

56. Koo WT, Jang JS, Choi SJ, Kim ID (2017) Metal-Organic Frameworks for Chemiresistive Sensors. ACS Appl Mater Inter 9(11): 18069. 
57. Mirzaei A, Hashemi B, Janghorban K (2016) $\alpha$-Fe2O3 based nanomaterials as gas sensors. J Mater Sci Mater Electron 27: 3109.

58. Jiang Z, Zhao R, Sun B, Nie G, Ji H, et al. (2016) Highly sensitive acetone sensor based on Eu-doped $\mathrm{SnO}_{2}$ electrospun nanofibers. Ceram Int 42(14): 1588115888.

59. Sensor composition for acetone detection in breath. Patents US 9.470,675 B2, EP2845009B1.

60. Aroutiounian VM (2015) Metal Oxide Gas Sensors Decorated with Carbon Nanotubes. Lith J Phys 55: 319329.

61. Narjinary M, Rana P, Sen A, Pal M (2017) Enhanced and selective acetone sensing properties of SnO2-MWCNT nanocomposites: Promising materials for diabetes sensor. Mater Des 115: 158.

62. Cao Z, Wang Y, Li Z, Yu N (2016) Hydrothermal Synthesis of $\mathrm{ZnO}$ Structures Formed by High-Aspect-Ratio Nanowires for Acetone Detection. Nanoscience Res Lett 11: 347.

63. Aroutiounian VM, Hovhannisyan A (2020) Breath Semiconductor Metal Oxide Gas Detector using Arduino Nano. Biomed J Sci \& Tech Res 27(1): 20452-20453.

64. Yang N, Chen X, Ren T, Zhang P, Yang D, et al. (2015) Carbon nanotube based biosensors. Sens Actuators B 207(Part A): 690-715.

65. Clark LC, Lyons C (1962) Electrode systems for continuous monitoring in cardiovascular surgery. Ann N Y Acad Sci 102: 29-45.

66. Raicopol M, Pruna A, Damian C, Pilan L (2013) Functionalized single-walled carbon nanotubes/ polypyrrole composites for amperometric glucose biosensors. Nanoscale Res Lett 316: 1-12.

67. Guo X (2013) Single-molecule electrical biosensors based on single-walled carbon nanotubes. Adv Mater 25(25): 3397-3408.

68. Allen BL, Kichambare PD, Star A (2007) Carbon Nanotube Field-Effect-Transistor-Based Biosensors. Adv Mater 19(11): 1439-1446.

69. Thévenot DR, Toth K, Durst RA, Wilson GS (2001) Electrochemical biosensors: recommended definitions and classification. Biosens Bioelectron 16(1-2): 121131.

70. Byon HR, Choi HC (2006) Network single-walled carbon nanotube-field effect transistors (SWNT-FETs) with increased Schottky contact area for highly sensitive biosensor applications. J Am Chem Soc 128(7): 21882202.

71. Tang XW, Bansaruntip S, Nakayama N, Yenilmez E, Chang YL, et al. (2006) Carbon nanotube DNA sensor and sensing mechanism. Nano Lett 6(8): 1632-1636.

72. Kim MJB, Woo S, Kim JW, Ahmed S, Subramanian S (2020) A review of review on applications of carbon nanotubes and their modifications for different comtaminants removal. J Critical reviews 7: 2923-2928.

73. Gruner G (2006) Carbon nanotube transistors for biosensing applications. Analyt. Bioanalytical Chemistry 384: 322-335.

74. Nie C, Pan L, Li H, Chen T, Lu T, etal. (2012) Electrophoretic deposition of carbon nanotubes film electrodes for capacitive deionization. J Electroanal Chem 666: 85-98.

75. Anker JN, Hall WP, Lyandres O, Shah NC, Zhao J, et al. (2009) iosensing with plasmonic nanosensors. Macmillan Publishers Ltd, London, UK, pp: 308-319.

76. Farrera C, Torres A, Feliu F (2017) Carbon Nanotubes as Optical Sensors in Biomedicine. ACS Nano 11(11): 10637-10643.

77. Shao L, Gao Y, Yan F (2011) Semiconductor quantum dots for biomedicial applications. Sensors 11(12): 1173611761.

78. Ramgir NS, Yang Y, Zacharias M (2010) Nanowire-based sensors. Small 6(16): 1705-1722.

79. Chen Z, Zhang XX, Yang R, Zhu Z, Chen Y, et al. (2011) Single-walled carbon nanotubes as optical materials for biosensing. Nanoscale 3(5): 1949-1956.

80. Liu Y, Dong X, Chen P (2012) Biological and chemical sensors based on graphene materials. Chem Soc Rev 41(6): 2283-2307.

81. Shen J, Zhu Y, Yang X, Li A (20120 Graphene quantum dots: emergent nanolights for bioimaging, sensors, catalysis and photovoltaic devices. Chem Commun 48: 3686-3699.

82. Gao C, Guo Z, Liu J-H, Huang X-J (2012) The new age of carbon nanotubes: an updated review of functionalized carbon nanotubes in electrochemical sensors. Nanoscale 4: 1948-1963.

83. Liu Z, Tabakman S, Welsher K, Dai H (2009) Carbon nanotubes in biology and medicine: In vitro and in vivo 
detection, imaging and drug delivery. Nano Res 2: 85120.

84. Yang W, Ratinac KR, Ringer SP, Thordarson P, Gooding JJ, et al. (2010) Carbon Nanomaterials in Biosensors: Should You Use Nanotubes or Graphene?. Angew Chem Int Ed 49(12): 2114.

85. Boghossian AA, Zhang J, Barone PW, Reuel NF, Kim JH, et al. (2011) Near-Infrared Fluorescent Sensors based on Single-Walled Carbon Nanotubes for Life Sciences Applications. Chem Sus Chem 4(7): 848-863.

86. Kim SJ, Choi SJ, Jang JS, Cho HJ, Kim ID (2017) Innovative Nanosensor for Disease Diagnosis. Acc Chem Res 50(7): 1587-1596.

87. Alvarez MM, Aizenberg J, Analoui M, Andrews AM, Bisker G, et al. (2017) Emerging Trends in Micro- and Nanoscale Technologies in Medicine: From Basic Discoveries to Translation. ACS Nano 11(6): 5195-5214.

88. Kruss S, Hilmer AJ, Zhang J, Reuel NF, Mu B, et al. (2013) Carbon nanotubes as optical biomedical sensors. Adv Drug Deliv Rev 65: 1933-1950.

89. Eatemadi A, Daraee H, Karimkhanloo H, Kouli M, Zarghami N, et al. (2014) Carbon nanotubes: properties, synthesis, purification, and medical applications. Nanoscale Research Letters 9: 393.

90. Iverson NM, Barone PW, Shandell M, Trudel LJ, Sen S, et al. (2013) In Vivo Biosensing Via Tissue Localizable Near Infrared Fluorescent Single Walled Carbon Nanotubes. Nat Nanotechnol 8: 873-880.

91. Ménard-Moyon C, Venturelli E, Fabbro C, Samori CK, Ros TD, et al. (2010) The alluring potential of functionalized carbon nanotubes in drug discovery. Expert Opin Drug Discov 5(7): 691-707.

92. Wu Y, Phillips JA, Liu H, Yang R, Tan W, et al (2008) Carbon nanotubes protect DNA strands during cellular delivery. ACS Nano 2(10): 2023-2030.

93. Bisker G, Dong J, Park HD, Iverson NM, Ahn J, et al. (2016) Protein-targeted corona phase molecular recognition. Nat Commun 7: 1-8.

94. Zhang J, Landry MP, Barone PW, Kim JH, Boghossian AA, et al. (2013) Molecular recognition using corona phase complexes made of synthetic polymers adsorbed on carbon nanotubes. Nat Nanotechnol 8(12): 959-968.

95. Beyene AG, Delevich K, Yang SJ, Landry MP (2018) New Optical Probes Bring Dopamine to Light. Biochemistry 57(45): 6379-6381.
96. Dinarvand M, Neubert E, Meyer G, Selvaggio A (2019) Near-infrared imaging of serotonin release from cells with fluorescent nanosensors. Nano Lett 19: 6604-6611.

97. Hendler Neumark A, Bisker G (2019) Fluorescent SingleWalled Carbon Nanotubes for Protein Detection. Sensors 19: 5403.

98. Ahn J-H, Kim J-H, Reuel NF, Barone PW, Boghossian AA, et al. (2011) Label-free, single protein detection on a nearinfrared fluorescent single-walled carbon nanotube/ protein microarray fabricated by cell-free synthesis. Nano Lett 11(7): 2743-2752.

99. Reuel NF, Ahn JH, Boghossian (2010) Nanotube array for optical detection of protein-protein interactions. US patent US10,215,752.

100. Pan J, Li F, Choi JH (2017) Single-walled carbon nanotubes as optical probes for bio-sensing and imaging. J Mater Chem B 5: 6511-6522.

101. Aroutiounian VM (2021) On Non-Invasive Measurements of Exhaled Aceton Using Metal Oxide Nanosensors. Journal of Nanomedicine \& Nanotechnology 12: 560.

102. Alizadeh N, Jamalabadi H, Tavoli F (2020) Breath Acetone Sensors as Non-Invasive Health Monitoring Systems: A Review. IEEE Sensors J 20(1): 5-31.

103. Han ZJ, Rider A, Ishaq M, Kumar Sh, Kondyurin A, et al. (2013) Carbon nanostructures for hard tissue engineering. RSC Adv 3(28): 11058-11072.

104. Nemeth Z, Perter N, Szekeres G, Schabikowski M, Schrantz K, et al. (2016) Enhanced virus filtration in hybrid membranes with MWCNT nanocomposite. R Soc Open Sci 6(1): 181294.

105. Meng X, Stout DA, Sun L, Beingessner RL, Fenniri H, et al. (2013) Novel injectable biomimetic hydrogels with carbon nanotubes for myocardial applications. J Biomed Mater Res 101(4): 1095-1102.

106. Mooney E, Mackle JN, Blond DJ, O'Cearbhaill, Shaw $G$, et a. (2012) The electrical stimulation of carbon nanotubes to provide a cardiomimetic cue to MSCs. Biomaterials 33(26): 6132-6139.

107. Sheikhpour M, Golbabaie A, Kasaeian A (2017) Carbon nanotubes: a review of novel strategies for cancer diagnosis and treatment. Mater Sci Eng C 76: 1289-1304.

108. Badrzadeh F, Rahmati-Yamchi M, Badrzadeh K (2016) Drug delivery and nanodetection in lung cancer. Artif Cells Nanomed Biotechnol 44(2): 618-634. 
109. Sheikhpour M, Naghinejad M, Kasaeian A, Lohrasbi A, Shahraeinis SS, et al. (2020) The Applications of Carbon Nanotubes in the Diagnosis and Treatment of Lung Cancer: A Critical Review. International Journal of Nanomedicine 15: 7063-7078.

110. Kayat J, Gajbhiye V, Tekade RK, Jain NK (2011) Pulmonary toxicity of carbon nanotubes: a systematic report. Nanomedicine 7: 40-49.

111. Kim JS, Song KS, Joo HJ, Lee JH, Yu IJ (2010) Determination of cytotoxicity attributed to multiwall carbon nanotubes (MWCNT) in normal human embryonic lung cell (WI-38) line. J Toxical Environ Health A 73(21-22): 1521-1529.

112. Han ZJ, Rider A, Ishaq M, Kumar Sh, Kondyurin A, et al. (2013) Carbon nanostructures for hard tissue engineering. RSC Adv 3(28): 11058-11072.

113. Pacurari M, Castranova V, Vallyathan VJ (2010) Single-and multi-wall carbon nanotubes versus asbestos: are the carbon nanotubes a new health risk to humans? J Toxical Environ Health A 73(5): 378-395.

114. Nasser IM, Abu-Naser SS (2019) Lung cancer detection using artificial neural network. Int J Eng Inf Syst 3(3): 17-23.

115. Zhou J, Huang ZA, Kumar U, Chen DD (2017) Review of recent developments in determining volatile organic compounds in exhaled breath as biomarkers for lung cancer diagnosis. Anal Chim Acta 996: 1-9.

116. Shakeel PM, Burhanuddin MA, Desa MI (2019) Lung cancer detection from CT image using improved profuse clustering and deep learning instantaneously trained neural networks. Measurement 145: 702-712.

117. Stueckle TA, Davidson DC, Derk R, Wang P, Friend S, et al. (2017) Effect of surface functionalizations of multi- walled carbon nanotubes on neoplastic transformation potential in primary human lung epithelial cells. Nanotoxicology 11(5): 613-624.

118. Gasparri R, Sedda G, Spaggiari L (2018) The Electronic Nose's Emerging Role in Respiratory Medicine. Sensors 18(9): 3029.

119. Khanmohammadi A, Aghaie A, Vahedi E, Qazvini A, Ghanei M, et al. (2020) Electrochemical biosensors for the detection of lung cancer biomarkers: a review. Talanta 206: 120251.

120. Zhou L, Forman HJ, Ge Y, Lunec J (2017) Multi-walled carbon nanotubes: a cytotoxicity study in relation to functionalization, dose and dispersion. Topical In Vitro 42: 292-298.

121. Park CH, Schroeder V, Kim BJ, Swager TM (2018) Ionic liquid-carbon nanotube sensor arrays for human breath related volatile organic compounds. ACS Sens 3(11): 2432-2437.

122. Aasi A, Aghaei SM, Panchapakesan B (2020) A Density Functional Theory (DFT) study on the interaction of toluene with transition metal decorated carbon nanotubes: a promising platform for early detection of lung cancer from human breath. Nanotechnology 31(41): 415707.

123. Choudhary M, Singh A, Kaur S (2014) Enhancing lung cancer diagnosis: electrochemical simultaneous bianalyte immunosensing using carbon nanotubeschitosan nanocomposite. Appl Biochem Biotechnol 174(3): 1188-1200.

124. Wan Q, Xu Y, Chen X, Xiao H (2018) Exhaled gas detection by a novel Rh-doped CNT biosensor for prediagnosis of lung cancer: a DFT study. Mol Phys 116(17): 2205-2212. 